\title{
Radical Cyclopolymerization of Divinyl Ethers. The Polymerization Kinetics and the Polymer Structure.*
}

\author{
Mitsuo TsuKino and Toyoki KunitaKe** \\ Department of Chemical Engineering, Kitakyushu Technical College, \\ Kokura-minami, Kitakyushu 803 and Department of Organic Synthesis, \\ Faculty of Engineering, Kyushu University, \\ Fukuoka 812, Japan.
}

(Received November 29, 1980)

\begin{abstract}
The radical polymerizations of divinyl ether (DVE), cis-propenyl vinyl ether (PVE) and 2-methylpropenyl vinyl ether $\left(\mathrm{CH}_{3}\right.$-PVE) were carried out with AIBN initiator. The polymers were composed of five-membered monocyclic units with pendent unsaturated groups and $[3,3,0]$ bicyclic units. The bicyclization was favored at low monomer concentrations and with methyl-substituted monomers. The microstructures of the polymers were determined by ${ }^{13} \mathrm{C}-\mathrm{NMR}$ spectroscopy, through extensive use of the model compounds. A common cyclopolymerization process has emerged from the data obtained. The monomers react exclusively at the unsubstituted vinyl group, and the trans ring closure produces five-membered monocyclic radicals which then propagate intermolecularly or cyclize to give trans-fused bicyclic units.

KEY WORDS ${ }^{13} \mathrm{C}$-NMR Spectroscopy / Cyclopolymerization / Poly(divinyl ether) / Poly(cis-propenyl vinyl ether) / Poly(2-methylpropenyl vinyl ether) /
\end{abstract}

Divinyl ether (DVE) has been known to give soluble polymers with highly cyclized structures by radical polymerization, and the structure of the cyclized unit has been inferred from the model experiments and from the kinetic data. ${ }^{1-3} \mathrm{We}$ recently examined the polymer structure by means of ${ }^{13} \mathrm{C}$-NMR spectroscopy and concluded that the cyclopolymerization process involved a fivemembered ring intermediate which would either propagate intermolecularly or cyclize to a bicyclic unit, ${ }^{4,5}$ as shown in Scheme 1. Interestingly, the cyclization process was highly stereoselective.

In the present study, we carried out a structural study on the cyclopolymers of cis-propenyl vinyl ether (PVE) and 2-methylpropenyl vinyl ether $\left(\mathrm{CH}_{3}-\mathrm{PVE}\right)$, and compared the effect of the polymerization condition on the polymer structure for each of three related monomers: DVE, PVE, and

* Contribution No. 611 from Department of Organic Synthesis.

** Correspondence should be sent to this author at the Fukuoka address.
$\mathrm{CH}_{3}$-PVE. Some kinetic studies were also carried out.

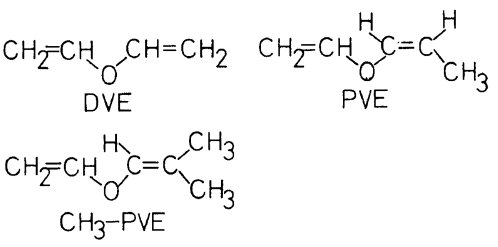

\section{EXPERIMENTAL}

\section{Materials}

The purification of DVE has been described. ${ }^{5}$ PVE was prepared by the isomerization of allyl vinyl ether obtained by the exchange reaction of $n$ butyl vinyl ether and allyl alcohol in the presence of $\mathrm{Hg}(\mathrm{OAc})_{2}$ according to the procedure of Watanabe et al. ${ }^{6}$ : bp $66-67^{\circ} \mathrm{C}$, lit ${ }^{6}$ bp $66-67^{\circ} \mathrm{C}$. The isomerization to PVE (cis-isomer) was performed with reference to the preparation of cis,cis-dipropenyl ether ${ }^{7}$ in the presence of potassium tert-butoxide in 

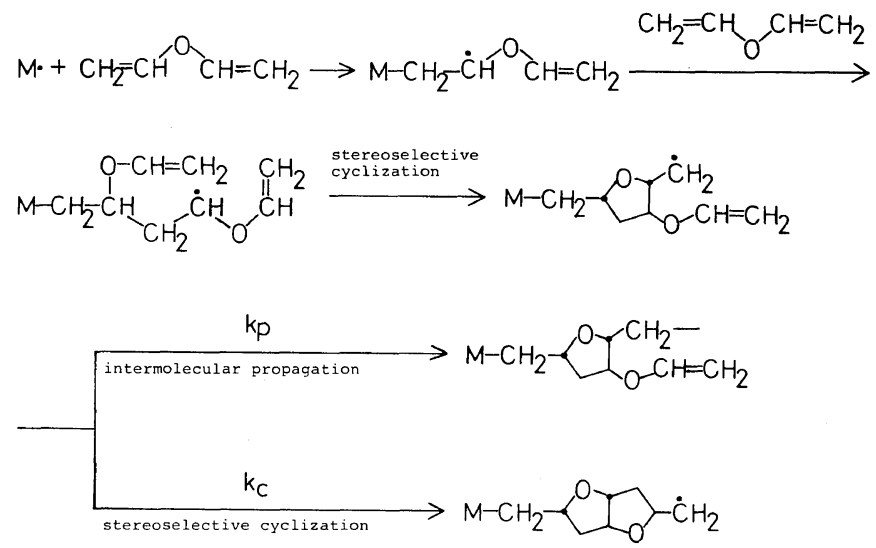

Scheme 1.

dimethylsulfoxide at room temperature for 10 days. PVE was separated by distillation under reduced pressure, washed with alkali and water, and redistilled: bp $61.5-62.5^{\circ} \mathrm{C} \quad\left(\right.$ lit $\left.^{6} \quad 61-62^{\circ} \mathrm{C}\right), d_{4}^{25}$ 0.7899 . The isomerization was virtually quantitative, but the trans isomer $(5 \%)$ was also formed.

Methallyl vinyl ether was similarly prepared by the exchange reaction of methallyl alcohol and methyl vinyl ether at $30^{\circ} \mathrm{C}$ in the presence of molecular sieve $4 \mathrm{~A}$ and a catalytic amount of $\mathrm{Hg}$ $(\mathrm{OAc})_{2}$, according to the procedure of Yuki et al ${ }^{8}$ : bp $89.0-89.5^{\circ} \mathrm{C}$ (lit. $87-88^{\circ} \mathrm{C},{ }^{6} 90^{\circ} \mathrm{C}^{8}$ ). The isomerization was carried out quantitatively in a way similar to that mentioned above for $90 \mathrm{~h}$ at $90^{\circ} \mathrm{C}$, to give pure $\mathrm{CH}_{3}-\mathrm{PVE}$, bp $85.6-87.5^{\circ} \mathrm{C}, d_{4}^{25} 0.7940$. The structure and purity of this monomer were confirmed by gas chromatography, ${ }^{1} \mathrm{H}$-NMR spectroscopy and elemental analysis.

Anal. Calcd for $\mathrm{C}_{6} \mathrm{H}_{10} \mathrm{O}: \mathrm{C}, 73.47 \%$; $\mathrm{H}, 10.20 \%$. Found: C, $73.01 \%$; H, $10.42 \%$.

Azobisisobutyronitrile (AIBN) was recrystallized from ethanol. Solvents were purified by the usual procedure.

\section{Polymerization}

Given amounts of monomer, AIBN, and benzene, when necessary, were placed in ampoules and subjected to the freeze-pump-thaw cycle several times. The ampoules were then sealed in vacuo and immersed in a constant temperature bath. The polymer was recovered by precipitation in methanol, purified by reprecipitation from benzene and methanol, and freeze-dried. The polymers were white powders, soluble in $\mathrm{CHCl}_{3}, \mathrm{CCl}_{4}$, etc.
Gelation occurred at conversions of $c a .3 \%$ in the bulk polymerization of DVE, but no gelation occurred for bulk PVE and $\mathrm{CH}_{3}-\mathrm{PVE}$ up to conversions of $30-40 \%$.

Poly(PVE)

Anal. Calcd for $\mathrm{C}_{5} \mathrm{H}_{8} \mathrm{O}: \mathrm{C}, 71.33 \% ; \mathrm{H}, 9.51 \%$. Found: C, $70.93 \%$; H, 9.52\%.

Poly $\left(\mathrm{CH}_{3}-\mathrm{PVE}\right)$

Anal. Calcd for $\mathrm{C}_{6} \mathrm{H}_{10} \mathrm{O}: \mathrm{C}, 73.47 \% ; \mathrm{H}, 10.20 \%$. Found: $\mathrm{C}, 73.06 \%$; H, $10.19 \%$.

\section{Hydrolysis}

The pendent propenyloxy groups of poly(PVE) and poly $\left(\mathrm{CH}_{3}-\mathrm{PVE}\right)$ were converted to hydroxy groups by hydrolysis of the polymers in mixtures of methanol and hydrochloric acid, as already done for poly(DVE). ${ }^{5}$ The complete removal of the pendent group was confirmed by NMR spectroscopy and the NMR data were consistent with the elemental analysis.

Poly(PVE) (hydrolyzed)

Anal. Calcd for $\left(\mathrm{C}_{5} \mathrm{H}_{8} \mathrm{O}\right)_{0.74}\left(\mathrm{C}_{2} \mathrm{H}_{4} \mathrm{O}\right)_{0.26}: \mathrm{C}$, $68.75 \%$; H, 9.46\%. Found: C, $67.91 \%$; H, $9.52 \%$.

Poly $\left(\mathrm{CH}_{3}-\mathrm{PVE}\right)$ (hydrolyzed)

Anal. Calcd for $\left(\mathrm{C}_{6} \mathrm{H}_{10} \mathrm{O}\right)_{0.74}\left(\mathrm{C}_{2} \mathrm{H}_{4} \mathrm{O}\right)_{0.26}: \mathrm{C}$, $70.88 \%$; H, $10.05 \%$. Found: C, $69.49 \%$; H, $9.95 \%$.

\section{Micellaneous}

The amount of the unsaturated pendent group in polymer was determined by ${ }^{1} \mathrm{H}-\mathrm{NMR}$ spectroscopy (Hitachi R-24B, $60 \mathrm{MHz}$ ) using the peak area of the vinyl methine proton or the propenyl methine proton (5.4-6.6 ppm). ${ }^{13} \mathrm{C}-\mathrm{NMR}$ spectroscopy was obtained under noise decoupling with a Bruker 


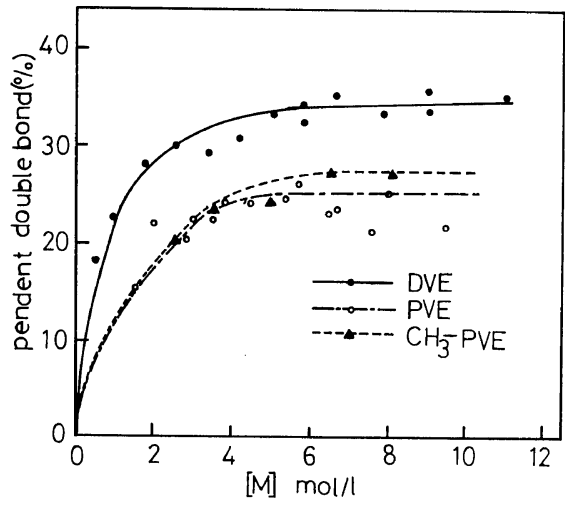

Figure 1. Content of the pendent double bond (PDB) in poly(divinyl ether)s. Polymerization conditions: $\mathrm{C}_{6} \mathrm{H}_{6}$ solvent, $60^{\circ} \mathrm{C}$. $\mathrm{PDB}$ is $100 \%$ provided that each monomer unit contains one pendent unsaturation.

WH-90 (22.63 MHz) instrument and a JEOL FX$100(25 \mathrm{MHz})$ instrument. The molecular weights of the polymer were determined by gel-permeation. chromatography: Toyo Soda Co., Model 802 UR. Three columns of different molecular-weight ranges were connected in series. Tetrahydrofuran was used as the eluent, and molecular weight was calculated using a calibration curve of monodisperse polystyrenes.

\section{RESULTS AND DISCUSSION}

\section{Polymerization Kinetics}

The monocyclic and bicyclic units in poly(DVE) are formed through a common intermediate. ${ }^{5}$ The same situation arises for poly(PVE) and poly $\left(\mathrm{CH}_{3}-\mathrm{PVE}\right)$. As will be discussed below, the pendent groups were invariably substituted vinyl groups (propenyl and methylpropenyl groups), and single five-membered intermediates were formed stereoselectively which produced the corresponding monocyclic and bicyclic units. The propagation occurred preferentially from the vinyl side.

Figure 1 shows the relationship between pendent unsaturation in polymer and monomer concentration. In all cases, the content of the pendent double bond (PDB) (i.e., the fraction of the monocyclic unit) increased with increasing monomer concentrations, reaching constant values at initial monomer concentrations from $3-5 \mathrm{moll}^{-1}$. The conversions were kept below $10 \%$. The peak pattern of ${ }^{13} \mathrm{C}$-NMR spectra did not change, in spite

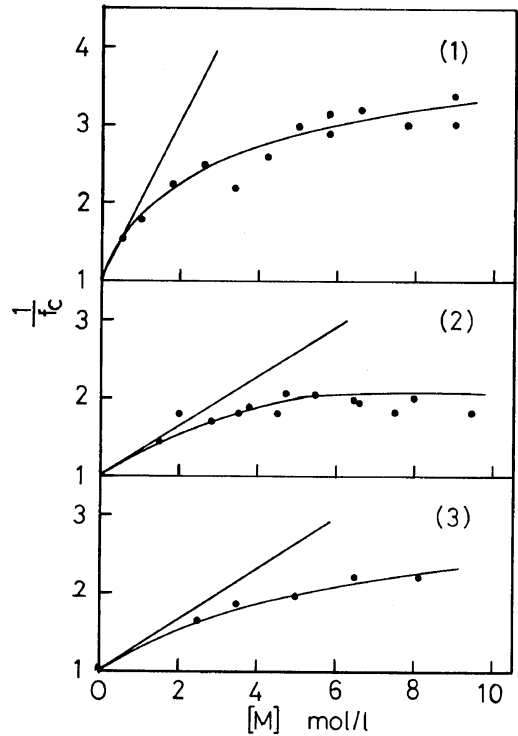

Figure 2. Plots of $1 / f_{\mathrm{c}}$ against the initial monomer concentration: (1) DVE; (2) PVE; (3) $\mathrm{CH}_{3}-\mathrm{PVE}$.

of variation in PDB. This means that the unit structures remain the same and that the PDB variation is caused by change in the extent of bicyclization. The extent of bicyclization is greater for poly $(\mathrm{PVE})$ and poly $\left(\mathrm{CH}_{3}-\mathrm{PVE}\right)$ than for poly(DVE).

The rates of the intermolecular propagation and the intramolecular cyclization from the monocyclic intermediate ( $R_{\mathrm{p}}$ and $R_{\mathrm{c}}$, respectively) are given for DVE by,

$$
\begin{aligned}
& R_{\mathrm{p}}=2 k_{\mathrm{p}}[\mathrm{M}][\mathrm{M} \cdot] \\
& R_{\mathrm{c}}=k_{\mathrm{c}}[\mathrm{M} \cdot]
\end{aligned}
$$

were $k_{\mathrm{p}}$ and $k_{\mathrm{c}}$ are the respective rate constants, and $[\mathrm{M}]$ and $[\mathrm{M} \cdot]$ are the concentrations of the monomer and the monocyclic radical intermediate, respectively.

Then,

$$
\frac{R_{\mathrm{p}}}{R_{\mathrm{c}}}=\frac{2 k_{\mathrm{p}}[\mathrm{M}][\mathrm{M} \cdot]}{k_{\mathrm{c}}[\mathrm{M} \cdot]}=2 \frac{k_{\mathrm{p}}}{k_{\mathrm{c}}}[\mathrm{M}]
$$

The extent of bicyclization is given by,

$$
f_{\mathrm{c}}=\frac{R_{\mathrm{c}}}{R_{\mathrm{p}}+R_{\mathrm{c}}}
$$

Therefore,

$$
\frac{1}{f_{\mathrm{c}}}=1+2 \frac{k_{\mathrm{p}}}{k_{\mathrm{c}}}[\mathrm{M}]
$$




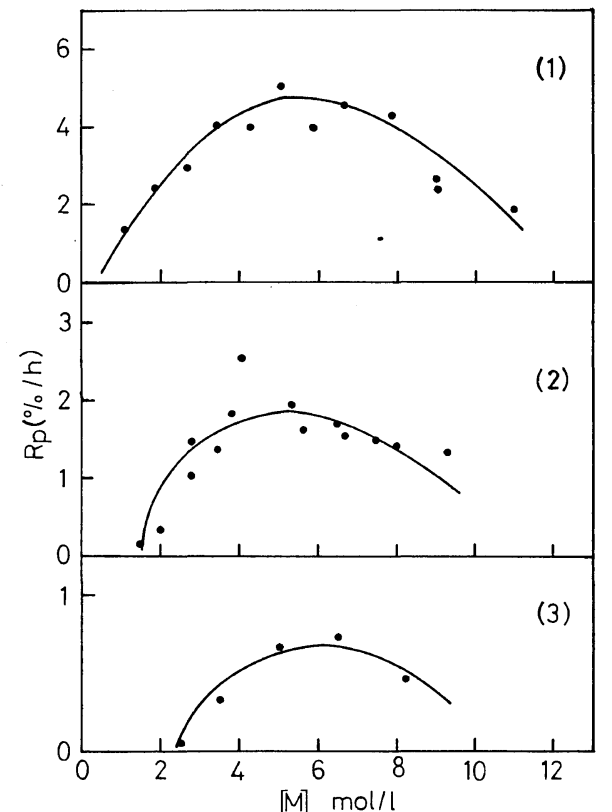

Figure 3. Rate of polymerization of divinyl ethers plotted against the initial monomer concentration: Polymerization conditions: $\mathrm{C}_{6} \mathrm{H}_{6}$ solvent, $60 \mathrm{C}$; AIBN $2.5 \times 10^{-2} \mathrm{~mol} \mathrm{1}^{-1}$ for DVE (1), $2.5 \times 10^{-1} \mathrm{~mol} \mathrm{l}^{-1}$ for PVE (2), $4.0 \times 10^{-1} \mathrm{~mol} \mathrm{l}^{-1}$ for $\mathrm{CH}_{3}-\mathrm{PVE}$ (3).

In the case of $\mathrm{PVE}$ and $\mathrm{CH}_{3}-\mathrm{PVE}$ monomers,

$$
R_{\mathrm{p}}=k_{\mathrm{p}}[\mathrm{M}][\mathrm{M} \cdot]
$$

since only the vinyl group is involved in the propagation. Therefore,

$$
\frac{1}{f_{\mathrm{c}}}=1+\frac{k_{\mathrm{p}}}{k_{\mathrm{c}}}[\mathrm{M}]
$$

Figure 2 shows the plots of $1 / f_{\mathrm{c}}$ against [M]. Linear relationships are not observed against the theoretical prediction, and $1 / f_{\mathrm{c}}$ tends to saturate at high monomer concentrations. It is suspected that the solvent effect of the monomers becomes influential at higher concentrations. The $k_{\mathrm{c}} / k_{\mathrm{p}}$ values were estimated tentatively from the initìal slopes: 2 mol $1^{-1}$ for DVE and $3 \mathrm{~mol}^{-1}$ for PVE and $\mathrm{CH}_{3}-$ PVE. These values indicate that the bicyclization process is more favorable when the pendent vinyl group is substituted.

Figure 3 shows the relationship between the initial rate of polymerization and the monomer concentration. The polymerization rate shows maxima at $[\mathrm{M}]=4-6 \mathrm{moll}^{-1}$. The rate decrease at

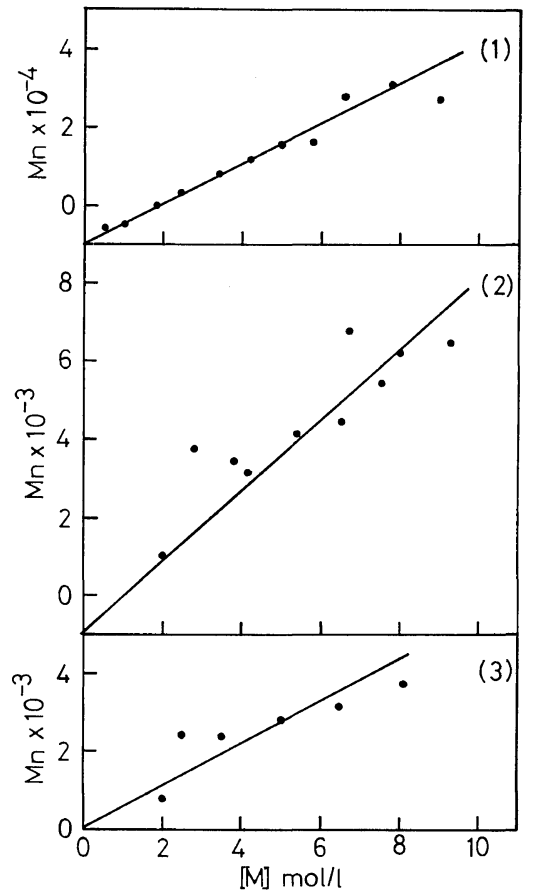

Figure 4. Molecular weight vs. initial monomèr concentration: (1), DVE; (2), PVE; (3), $\mathrm{CH}_{3}-\mathrm{PVE}$. Polymerization conditions are the same as those of Figure 3.

high monomer concentrations may be also attributed to the solvent effect of the monomer. The molecular weight of the polymers increased linearly with the monomer concentration as shown in Figure 4. The molecular weight of poly(DVE) was in the range of $5 \times 10^{3}$ to $4 \times 10^{4}$ under the conditions used, but those of poly(PVE) and poly $\left(\mathrm{CH}_{3}-\mathrm{PVE}\right)$ were $2000-8000$ and $1000-4000$, respectively. Methyl substitution decreases the molecular weight considerably.

\section{Structure of Poly (DVE)}

The structure of Poly(DVE) was determined in our previous paper ${ }^{5}$ by comparing the ${ }^{13} \mathrm{C}-\mathrm{NMR}$ spectrum of the polymer with the chemical shifts calculated using model compounds (methylcyclopentanes and 2,5-dimethylcyclopentane). Recently, there were published ${ }^{13} \mathrm{C}$-NMR data of more appropriate model compounds. ${ }^{9}$ These new data on substituted tetrahydrofurans were combined with previously used data on cyclopentanes ${ }^{10}$ and cyclohexanols ${ }^{11}$ in order to estimate the chemi- 


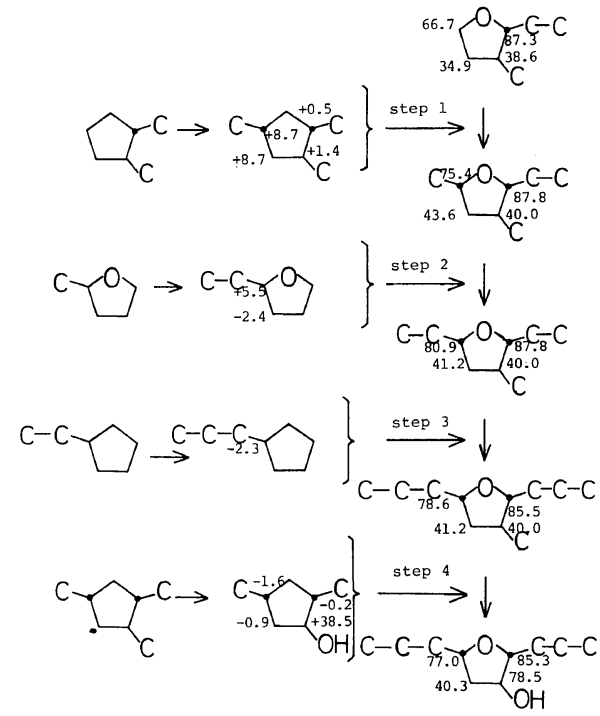

Scheme 2.

cal shifts of the model compounds shown in Scheme 2.

In step 1 of this scheme, the chemical shift differences between the dimethyl- and trimethylcyclopentanes are added to the observed chemical shifts of trans-2-ethyl-3-methyltetrahydrofuran so as to estimate the chemical shift of the ring carbons of the corresponding trisubstituted tetrahydrofuran. The effect of the substitaent elongation is considered in steps 2 and 3 . Step 4 is concerned with the conversion of methyl to hydroxyl groups.

Four configurational isomers are present for 2,5di-n-propyl-3-hydroxytetrahydrofuran, and the chemical shifts of the ring carbon of these isomers were estimated by procedures similar to that of Scheme 2. The results are summarized and compared with the observed chemical shifts in Figure 5.

The calculated chemical shifts for isomers $\mathbf{A}$ and $\mathbf{B}$ (trans ring closure units) are in good agreement with the observed values. The agreement with the experiment is better in the newly estimated set of chemical shift than the previous estimation, particularly for ring carbon 4.

The chemical shifts of the ring carbon of the bicyclic unit were estimated using the new data obtained by the procedure described in Scheme 3 of ref 5. Eight configurationally isomeric units are present for the bicyclic unit, and the chemical shifts estimated for the ring carbon are compared with the observed values in Figure 6 . The best agreements

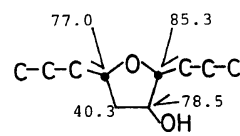

A
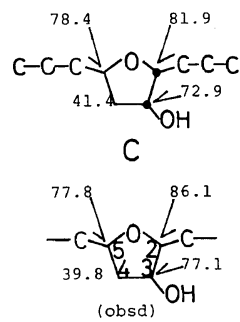

Figure 5. Comparison of the observed chemical shift of the hydrolyzed monocyclic unit of poly(DVE) with those estimated for 2,5-dipropyl-3-hydroxytetrahydrofurans.
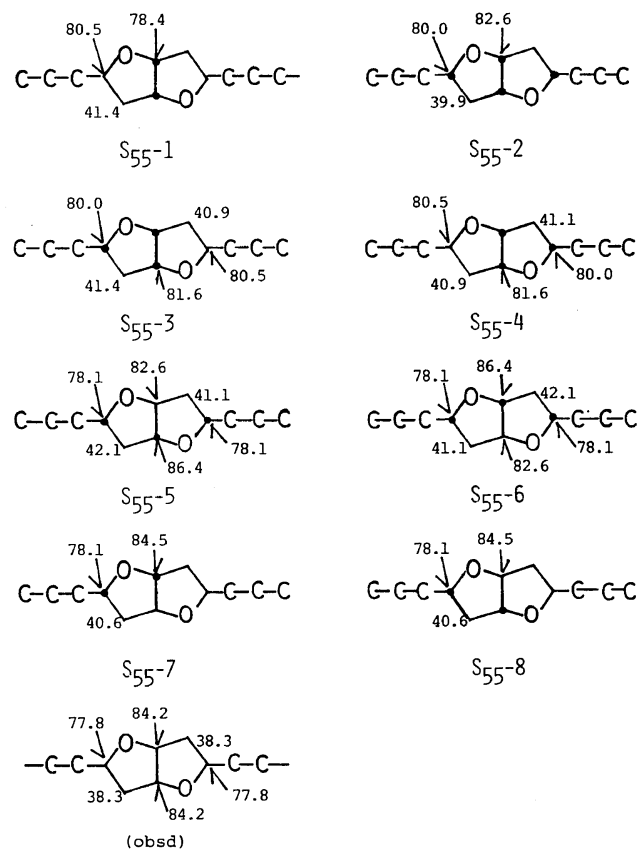

Figure 6. Comparison of the observed chemical shift of the bicyclic unit of poly(DVE) with those estimated for the model compounds.

between calculation and experiment were obtained for $\mathbf{S}_{55} \mathbf{- 7}$ and $\mathbf{S}_{55} \mathbf{- 8}$ : both of these structures are products of the trans ring closure. The bicyclic structure is formed from a cyclic radical intermediate common to the monocyclic unit. ${ }^{5}$ Therefore, bicyclic unit $\mathbf{S}_{55} \mathbf{- 7}$ and $\mathbf{S}_{55} \mathbf{- 8}$ must be form- 


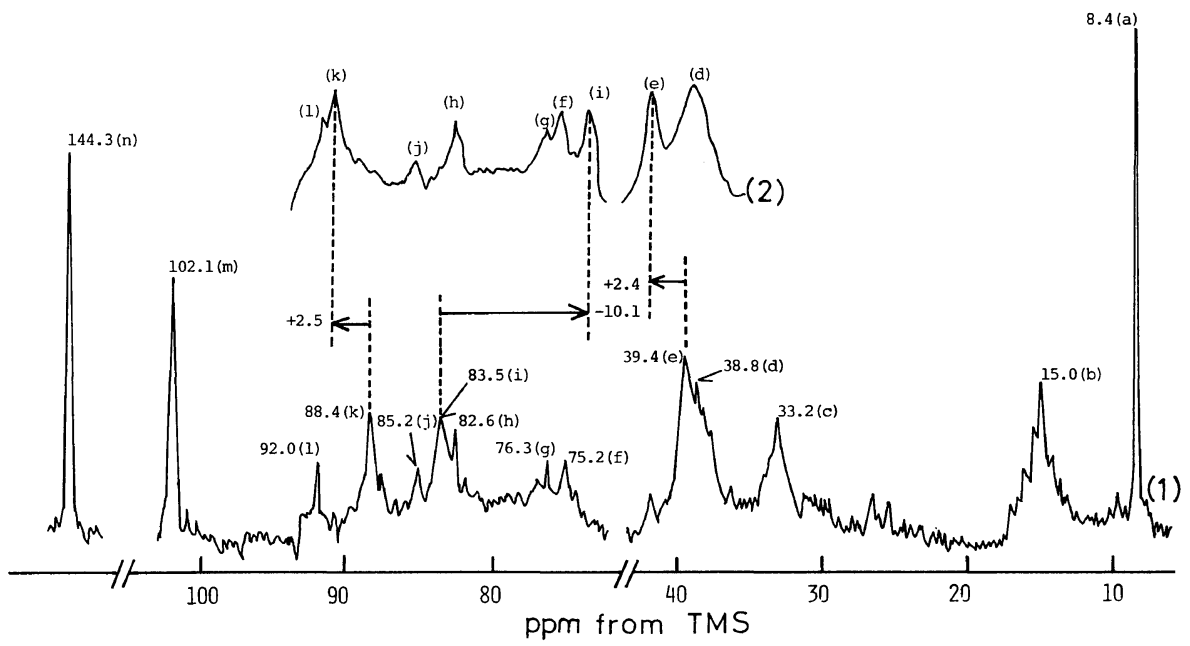

Figure 7. ${ }^{13} \mathrm{C}-\mathrm{NMR}$ spectra of poly(PVE) and its hydrolysis product. The peak shift upon hydrolysis is indicated by arrows. (1) poly $(\mathrm{PVE})$ obtained at $[\mathrm{M}]=4.7 \mathrm{~mol}^{-1}$, in $\mathrm{C}_{6} \mathrm{H}_{6}$ solvent at $60^{\circ} \mathrm{C}$; $[\mathrm{PDB}]=26.5^{\circ}$; the spectrum measured in $\mathrm{C}_{6} \mathrm{D}_{6} / \mathrm{C}_{6} \mathrm{H}_{6}$ at $42 \mathrm{wt} \%$. (2) the hydrolyzed polymer; the spectrum measured in $\mathrm{C}_{6} \mathrm{D}_{6} / \mathrm{CH}_{3} \mathrm{OH}$ at $47 \mathrm{wt} \%$.

ed from monocyclic intermediates corresponding to $\mathbf{A}$ and $\mathbf{B}$ of Figure 5, respectively.

\section{Structure of poly (PVE)}

Figure 7 is a ${ }^{13} \mathrm{C}-\mathrm{NMR}$ spectrum of poly(PVE) and a partial spectrum of the hydrolyzed product. These peaks can be assigned in a way similar to that used for poly(DVE). The peaks of the pendent unsaturation are composed of those of propenyl methyl carbon (a), $\beta$-carbon (m), and $\alpha$-carbon (n). These peaks disappear completely upon hydrolysis, as expected. The hydrolysis causes an up-field shift of peak $i$ and down-field shifts of peaks e and $k$. Therefore, peak $\mathrm{i}$ is assigned to the $\alpha$ carbon with respect to pendent group and peaks e and $\mathrm{k}$ to the $\beta$ carbon with respect to the pendent group. These assignments are consistent with monocyclic structure $\mathbf{I}$.

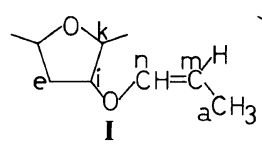<smiles>C=C1CC(C)OC(C)C1C=CC</smiles>

The six-membered ring with the pendent propenyl group (II) cannot be compatible with these shift data, since the $\beta$-carbon in the six-membered ring should be located at $30-35 \mathrm{ppm}$, and the hydrolysis does not cause any peak shift in this region.
The five-membered monocyclic unit may be formed by the propagation process shown in Scheme 3. There are four kinds of propagation

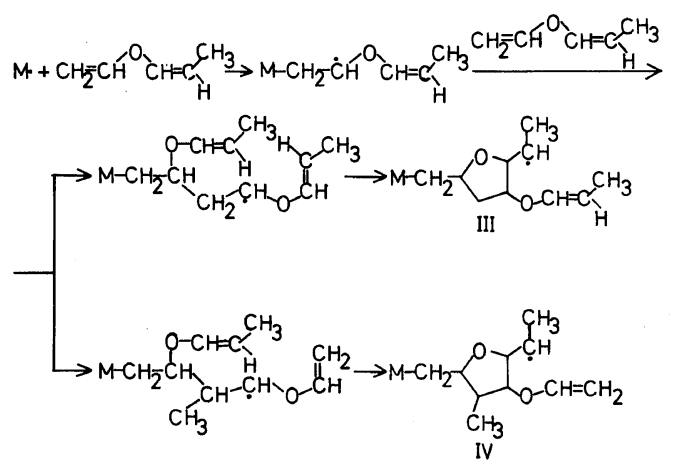
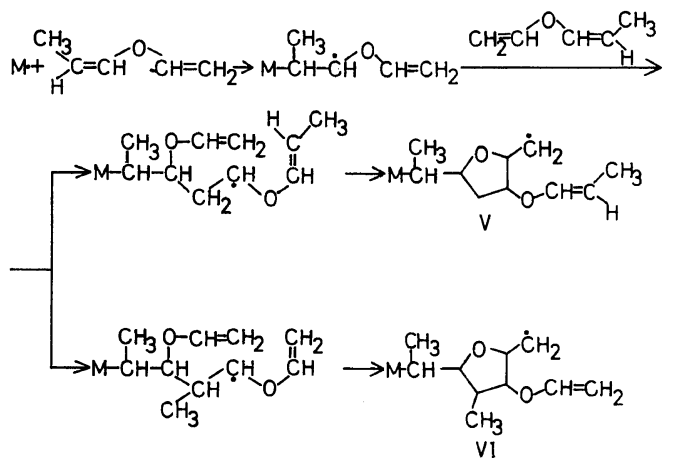

Scheme 3. 
routes which produce monocyclic radical intermediates III, IV, V, and VI. ${ }^{1} \mathrm{H}-\mathrm{NMR}$ and ${ }^{13} \mathrm{C}-\mathrm{NMR}$ spectral data indicate the absence of the pendent vinyl group and, therefore, intermediates IV and VI are excluded. Thus, the resulting monocyclic structure is represented by VII or $\mathbf{X}$ of Scheme 4 .

The steric structure of these monocyclic units can
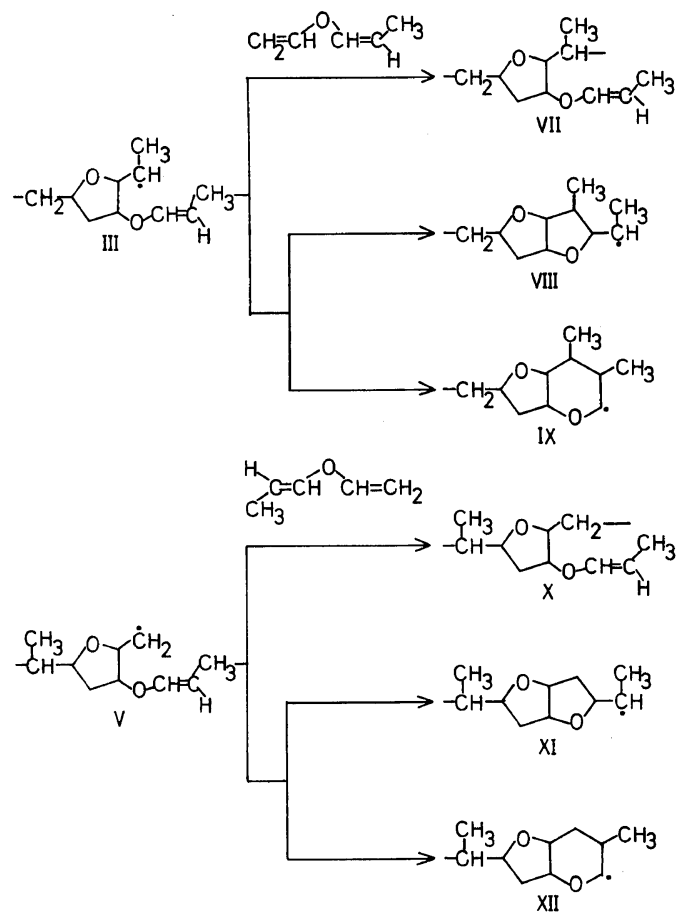

Scheme 4.
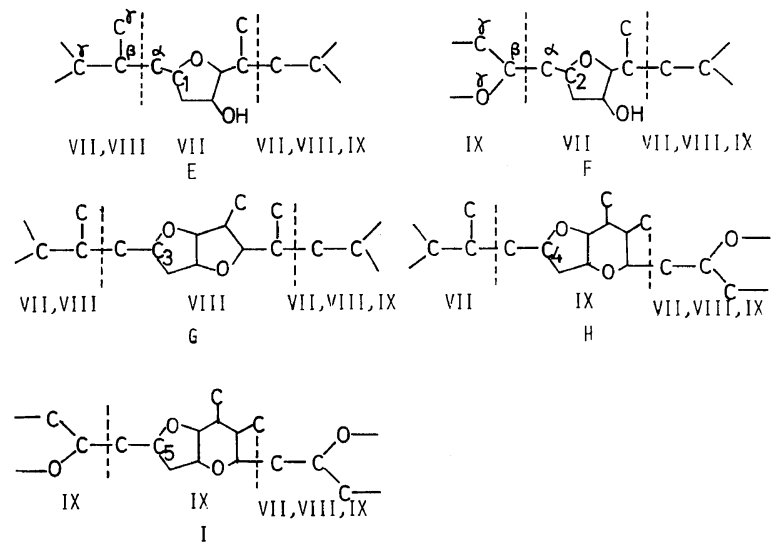

Figure 8. Linkages of the structural units of poly(PVE). be determined for their hydrolyzed structures by correcting the results of Figure 5 for the effect of additional methyl substitutents. However, before calculating the correction, the location of methyl substitution must be determined on the basis of the mode of connection of the monocyclic and bicyclic units.

In the $70-95 \mathrm{ppm}$ region (carbon next to the ether oxygen) of Figure 7, if peaks i, $k$, and $f$ are assigned, as mentioned above, to the ring carbons of the monocyclic unit, the remaining peaks $\mathrm{g}, \mathrm{h}, \mathrm{j}$, and 1 will be attributed to the ring carbons of the bicyclic unit. If it is assumed that there exist only one kind of bicyclic unit, four kinds of carbon adjacent to the ether oxygen should be present (see below). This is consistent with the spectral data. Furthermore, the spectral pattern does not vary, when the content of the pendent double bond is changed under different polymerization conditions. These results strongly suggest that a unique monocyclic intermediate (III or $\mathbf{V}$ of Scheme 4) is formed and that this intermediate gives monocyclic unit VII or $\mathbf{X}$ by intermolecular propagation or cyclizes to either of two possible bicyclic structures (VIII or IX from III and XI or XII from V).

Thus, if VII is present as the monocyclic unit, the coexisting bicyclic unit must be VIII or IX. Figure 8 shows all possible connections of the monocyclic (VII) and bicyclic (VIII and IX) units in polymer. The content of the pendent double bond determined by ${ }^{1} \mathrm{H}-\mathrm{NMR}$ spectroscopy indicates that the ratio of the monocyclic to bicyclic units varies from $7: 3$ to $5: 5$, depending on the monomer concentration. 

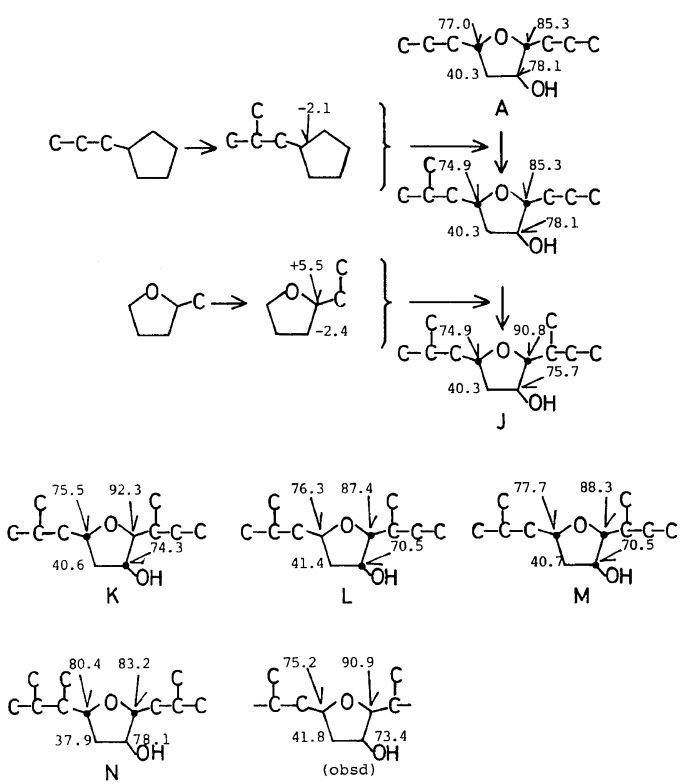

Scheme 5 .

Therefore, there must be monocyclic-to-monocyclic and bicyclic-to-bicyclic connections in addition to the monocyclic-to-bicyclic connection.

Combination $\mathbf{E}$ is produced by placing structures VII or VIII before VII and structures VII, VIII, or IX after VII. When VII and VIII are the only structural units present, $\mathbf{E}$ and $\mathbf{G}$ are the only combinations surrounding the monocyclic and bicyclic units, respectively. If, however, IX is present in place of VIII as the bicyclic unit, combinations $\mathbf{E}, \mathbf{F}$, $\mathbf{H}$ and $\mathbf{I}$ will be formed. These two possibilities are discriminated by looking at the number of peaks ascribable to the $\alpha$-carbon of the five-membered ring: $C_{1}$ to $C_{5}$ in $\mathbf{E}$ to $\mathbf{I}$ (Figure 8). Two of these methine carbons $\left(C_{1}\right.$ and $\left.C_{3}\right)$ are found when the polymer is composed of structures VII and IX. On the other hand, if VIII is replaced by IX, four of the methine carbons can be present: $\mathrm{C}_{1}, \mathrm{C}_{2}, \mathrm{C}_{4}$, and $\mathrm{C}_{5}$, corresponding to structures $\mathbf{E}, \mathbf{F}, \mathbf{H}$, and $\mathbf{I}$. The carbon chemical shift is probably different between $\mathrm{C}_{1}$ and $\mathrm{C}_{2}$ and between $\mathrm{C}_{4}$ and $\mathrm{C}_{5}$ since the ether oxygen in the $\gamma$ position causes a down-field shift of ca. 2.5 ppm..$^{9.10}$

It was mentioned above that there are three major peaks for the ring carbon adjacent to the ether oxygen in the monocyclic structure and four major peaks for the ring carbon adjacent to the ether oxygen in the bicyclic structure. The NMR data are

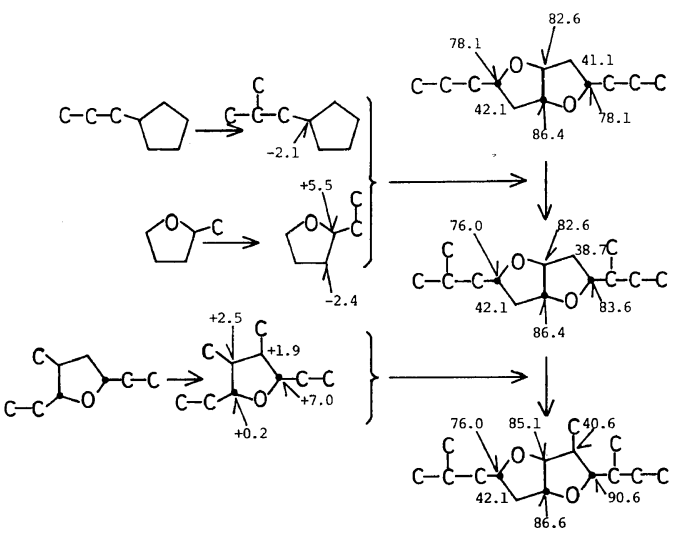

Scheme 6.

compatible only with the presence of the single combination for the monocyclic and bicyclic units, i.e., $\mathbf{E}$ and $\mathbf{G}$.

Now, the chemical shifts for the ring carbon in combination $\mathbf{E}$ (hydroxy derivative) are calculated by starting from the data of Figure 5. An example of the calculation procedure and the resulting chemical shifts for the four configurational isomers are given in Scheme 5. Among the four structures, $\mathbf{J}$ and $\mathbf{K}$ give reasonable agreement with the observed data. Also given in this scheme is the calculated chemical shift for structure $\mathbf{N}$ which corresponds to $\mathbf{X}$ in Scheme 4 (the configuration of $\mathbf{N}$ is the same as that of $\mathbf{J}$ ). Structure $\mathbf{N}$ does not give any satisfactory agreement. It may be concluded that in the propagation of propenyl vinyl ether, intermediate III, which possesses the configuration of $\mathbf{J}$ or $\mathbf{K}$, is involved and leads to the configurationally unique bicyclic unit VIII.

The steric structure of VIII can be inferred by the chemical shift difference estimated from the data given in Figure 6 for poly(DVE). An example of the calculation procedure is shown in Scheme 6 and the calculated chemical shifts are given in Figure 9.

We can now complete the assignment of the observed spectrum (Figure 7). The assignments of the broad peak $\mathrm{d}$ (38.8 ppm, carbon $\beta$ to the ether oxygen) and peak $\mathrm{g}$ (76.3 ppm, carbon $\alpha$ to the ether oxygen) are made fairly readily, as shown in Figure 9. The remaining $\alpha$-carbon peaks $\mathrm{h}, \mathrm{j}$, and $\mathrm{l}$ at 82.6 , 85.2 , and $92.0 \mathrm{ppm}$ cannot be assigned specifically, and structures in which these assignments are interchangeable may be sought. Then, cis-fused structures such as $\mathbf{S}_{55^{-}} \mathbf{9}$ and $\mathbf{S}_{55}-\mathbf{1 0}$ give calculated 

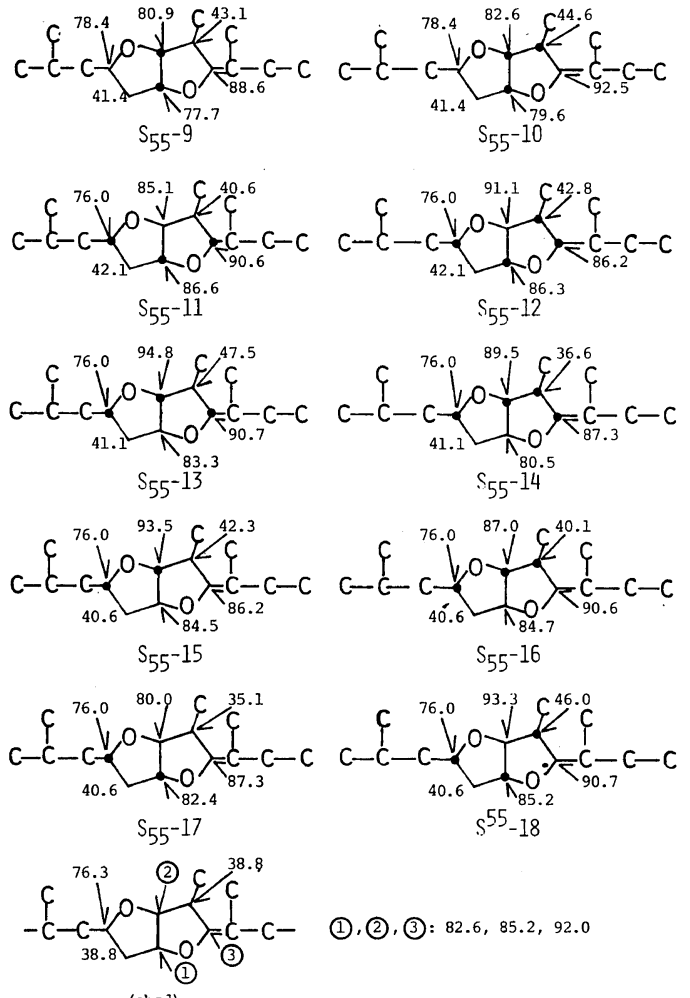

(1), (2), (3): $82.6,85.2,92.0$

(obsd)

Figure 9. Comparison of the observed chemical shift of the bicyclic unit of poly(PVE) with those estimated for the model compounds.

chemical shifts which are $4-5 \mathrm{ppm}$ away from the observed shifts, and may be excluded. Among the trans-fused structures, the following give fair agreement: $S_{55}-11, S_{55}-12, S_{55}-14, S_{55}-15, S_{55}-16$.

On the other hand, the chemical shift for exocyclic carbon can be calculated based on that of poly(DVE) as shown in Scheme 7 , by taking into account the configuration of the adjacent bicyclic ring. The influence of the steric difference in the monocyclic unit seems negligible, because the methyl carbons of cis- and trans-2,5-dimethyltetrahydrofuran show very similar chemical shifts. ${ }^{12}$ Structure $\mathbf{P}$ gives a better agreement with the observed values than structure $\mathbf{O}$. In addition, if three adjacent substituents on a five-membered ring are in the cis position, the central methyl substituent becomes, subjected to a strong stereocompression effect and an unusual high-field shift ( $\sim 7.5 \mathrm{ppm})$ would be observed, ${ }^{10}$ contrary to experimental observation. These considerations exclude $S_{55}-12, S_{55^{-}}$
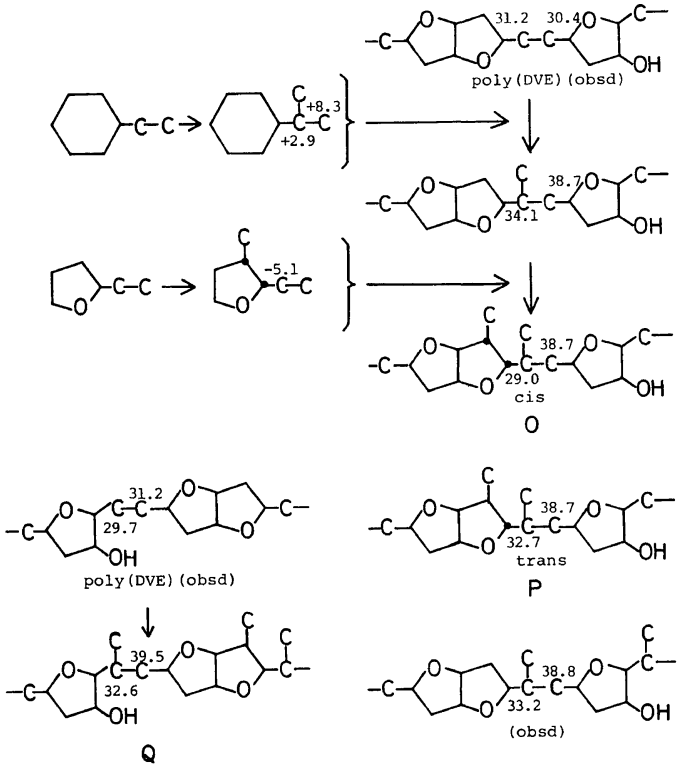

Scheme 7.

14 and $S_{55}-15$, and $S_{55}-11$ and $S_{55}-16$ remain as probable bicyclic units. $\mathbf{S}_{55} \mathbf{- 1 1}$ is formed from intermediate $K$ of scheme 5 and $S_{55}-16$ from intermediate $\mathbf{J}$, and it is concluded that poly(PVE) consists predominantly of combinations of $\mathbf{J}$ and $S_{55}-16$ or of $K$ and $S_{55}-11$.

\section{Structure of Poly $\left(\mathrm{CH}_{3}-\mathrm{PVE}\right)$}

Figure 10 shows a ${ }^{13} \mathrm{C}-\mathrm{NMR}$ spectrum of poly $\left(\mathrm{CH}_{3}-\mathrm{PVE}\right)$ and its hydrolysis product. The pendent unsaturation is due to 2-methylpropenyl group: peaks a and $b$ are assigned to the methyl carbon, peak $\mathrm{p}$ to the $\beta$-carbon and peak $\mathrm{q}$ to the methine carbon. On hydrolysis, these peaks disappeared completely, and three other peaks $\mathrm{f}, \mathrm{l}$, and $\mathrm{m}$ shifted. There were found seven peaks in the 70 $100 \mathrm{ppm}$ region for the carbon adjacent to the ether oxygen. If peak $i$ is assigned to the five-membered ring carbon along with peaks 1 and $m$ which shifts upon hydrolysis, the bicyclic ring carbon will be associated with peaks $\mathrm{j}, \mathrm{k}, \mathrm{n}$, and $\mathrm{o}$, and only one kind of major bicyclic unit. will be present as in poly(PVE). Considering the fact that the pendent group is 2-methylpropenyl and that only one kind each of the monocyclic and bicyclic units is present, the propagation process may be represented by Scheme 8 . The discussion on the combination of the cyclic unit performed for poly(PVE) is similarly 


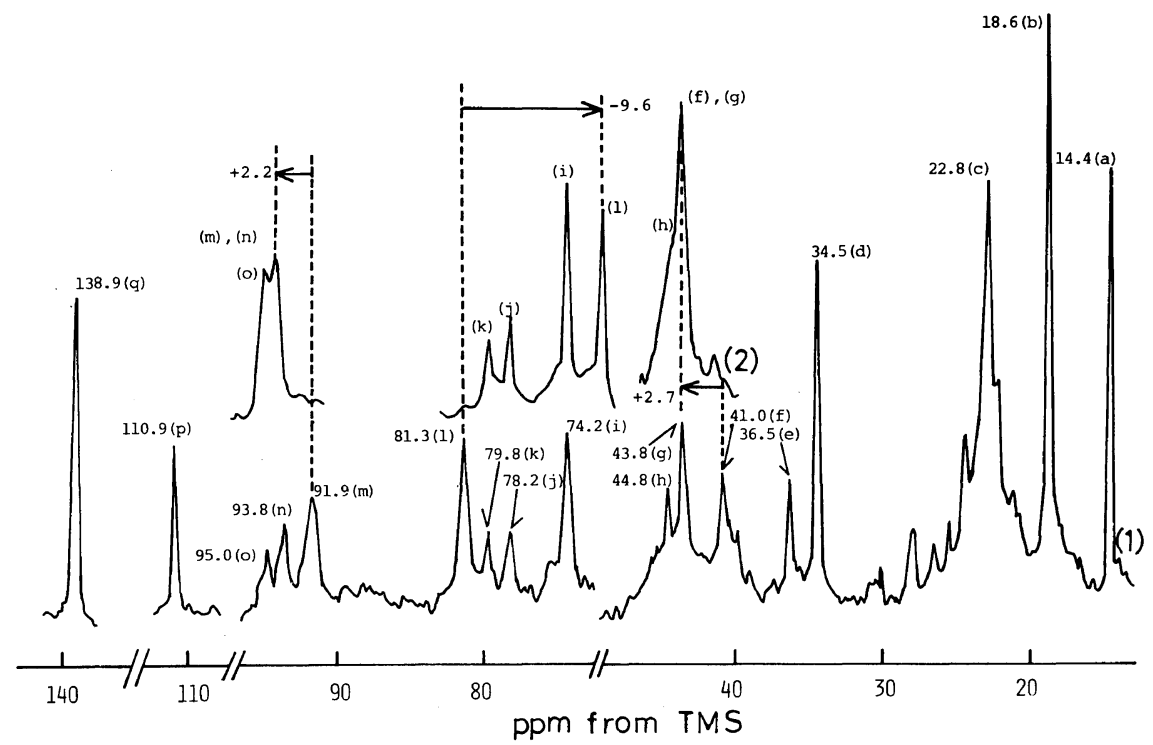

Figure 10. ${ }^{13} \mathrm{C}-\mathrm{NMR}$ spectra of poly $\left(\mathrm{CH}_{3}-\mathrm{PVE}\right)$ and its hydrolysis product. The peak shift upon hydrolysis is indicated by arrows. (1) poly $\left(\mathrm{CH}_{3}-\mathrm{PVE}\right)$ obtained by bulk $\left(8.1 \mathrm{~mol}^{-1}\right)$ polymerization at $60 \mathrm{C} ; \mathrm{PDB}]=26.1 \%$; the spectrum measured in $\mathrm{C}_{6} \mathrm{D}_{6} / \mathrm{C}_{6} \mathrm{H}_{6}$ at $42 \mathrm{wt} \%$. (2) hydrolyzed polymer, the spectrum measured in $\mathrm{C}_{6} \mathrm{D}_{6} / \mathrm{CH}_{3} \mathrm{OH}$ at $38 \mathrm{wt} \%$.
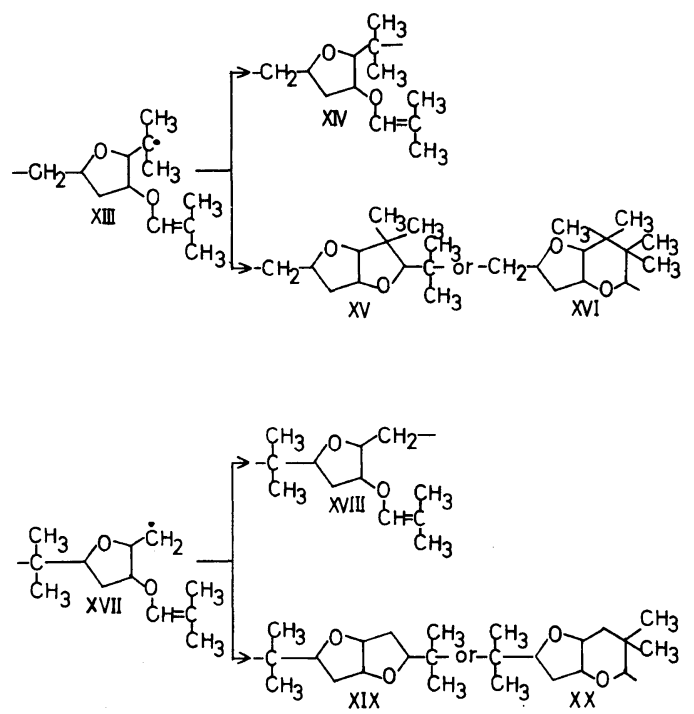

Scheme 8 .

applicable to poly $\left(\mathrm{CH}_{3}-\mathrm{PVE}\right)$ and leads to the conclusion that the major route of propagation involves cyclic radical intermediate XIII (but not XVII) which produces monocyclic unit XIV and bicyclic unit XV.

The steric structure of XIV was examined sub-
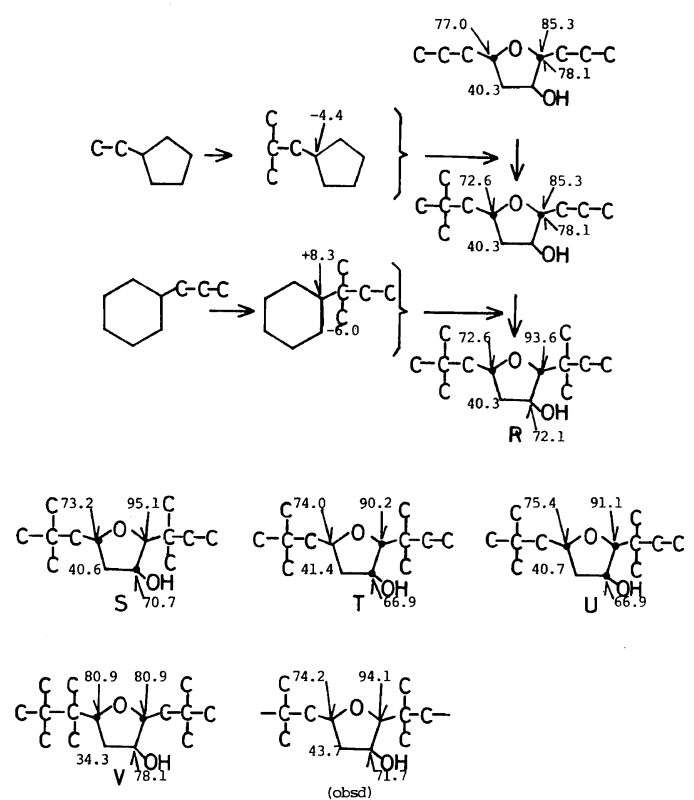

Scheme 9.

sequently. By a procedure similar to that of Scheme 7, the connection of XIV with XIV or XV was considered and the chemical shift of the ring carbon was calculated for the expected structure using the 


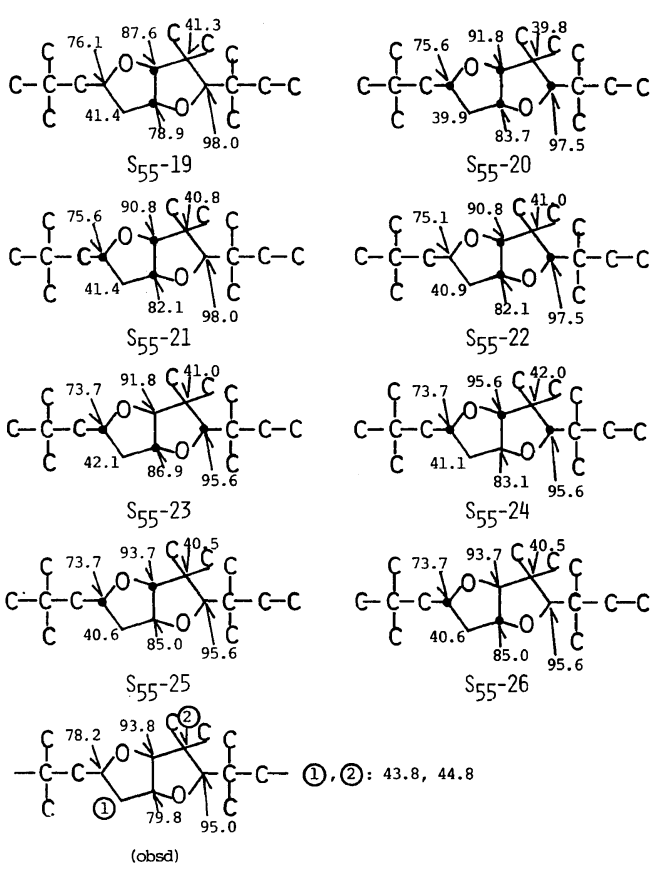

Figure 11. Comparison of the observed chemical shift of the bicyclic unit of poly $\left(\mathrm{CH}_{3}-\mathrm{PVE}\right)$ with those estimated for the model compounds.

procedure of Scheme 5. The procedure and the results are shown in Scheme 9. The chemical shifts in structures $\mathbf{T}$ and $\mathbf{U}$, produced by the $c i s$ ring closure, do not agree with the observed shifts. Structures $\mathbf{R}$ and $\mathbf{S}$ (trans ring closure) give better agreement although the chemical shifts of the ring methylene carbon are $c a .3 \mathrm{ppm}$ apart from the experimental data. Therefore, the monocyclic unit in the polymer must have the steric structure corresponding to either $\mathbf{R}$ or $\mathbf{S}$.

Structure $\mathbf{V}$ in Scheme 9 corresponds to one of the monocyclic structures produced through intermediate XVII of Scheme 8. The calculated chemical shifts for $\mathbf{V}$ are quite different from the experimental data, and the propagation cannot proceed via XVII. These results point to structure $\mathbf{X V}$ as the most probable bicyclic unit. Thus, the chemical shifts of the ring carbon of all the conceivable configurational isomers of $\mathbf{X V}$ was calculated as shown in Figure 11. This calculation was carried out by taking into account the connection of XV with XIV or $\mathbf{X V}$, as was also done for poly(DVE) and poly(PVE). The model compounds involve tetrahydrofurans with gem-dimethyl substituents ${ }^{13}$ in

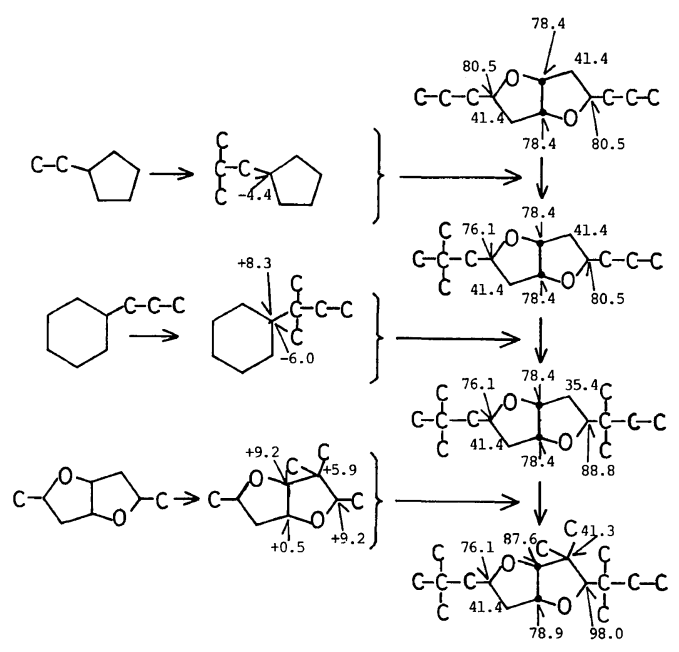

Scheme 10.

addition to those used previously. ${ }^{9-13}$ An example of the estimation procedure is shown in Scheme 10. The observed peaks for the bicyclic ring carbons were assigned as shown in Figure 11, by referring to the calculated value. Assignments for the $\alpha$ carbon (with respect to the ether oxygen) can be made relatively readily. However, the $\beta$-carbons could not be assigned definitely, and the subsequent assignment was made by alloting peaks at 43.8 and $44.8 \mathrm{ppm}$ to carbons 1 and 2 interchangeably.

Since the bicyclic structure is formed from monocyclic intermediates (with trans ring closure) corresponding to structures $\mathbf{R}$ and $\mathbf{S}$, the cis-fused bicyclic structures $\left(\mathbf{S}_{55}-19 \sim \mathbf{S}_{55}-22\right)$ cannot exist. At the same time, their calculated chemical shifts do not agree with observation. The trans-fused bicyclic structures $\left(\mathbf{S}_{55}-\mathbf{2 3} \sim \mathbf{S}_{55}-\mathbf{2 6}\right)$ do not show particularly good agreement, but $\mathbf{S}_{55}-\mathbf{2 4}$ shows the smallest discrepancy with the observed chemical shifts. Although the agreement is not necessarily sufficient due to the reason discussed below, $\mathbf{S}_{55}-\mathbf{2 4}$ or $\mathbf{S}_{55}-\mathbf{2 5}$ becomes the main bicyclic structure when the monocyclic radical is related to $\mathbf{R}$, and $\mathbf{S}_{55}-\mathbf{2 3}$ or $\mathbf{S}_{55}-\mathbf{2 6}$ becomes the main structure when the monocyclic intermediate is related to $\mathbf{S}$.

Figure 10 contains several peaks in the exocyclic carbon region at $20-30 \mathrm{ppm}$. They are attributed to the main-chain methylene carbons and to the gem-dimethyl carbons. The specific assignment of these peaks is difficult because of the considerable variation in the mode of ring connection and steric 
structure.

In the case of poly(DVE), the calculated chemical shifts for the bicyclic and monocyclic units agreed satisfactorily with the observed data. The agreement become less as the number of methyl substitution increased from poly(PVE) to poly $\left(\mathrm{CH}_{3}-\mathrm{PVE}\right)$. The conformation of the five-membered ring is not fixed, unlike that of the six-membered ring. In particular, the conformational flexibility of tetrahydrofurans and 1,3-dioxolanes which contain flexible ether oxygen as the ring member has been confirmed by their physical constants ${ }^{14}$ and by ${ }^{1} \mathrm{H}-\mathrm{NMR}^{14}$ and ${ }^{13} \mathrm{C}-\mathrm{NMR}{ }^{9,15}$ spectroscopies. It is conceivable that these flexible rings assume various conformations depending on the degree of substitution. Our calculation of the chemical shift was carried out by simple addition of the chemical shift difference due to introduction or conversion of substituents on the chemical shift of simpler model compounds. It is assumed in these calculations that the ring conformation is fixed. The limitation of this procedure is illustrated in the following examples where the calculated values are derived by corrections due to repeated conversions of methyl to isopropyl substituents.

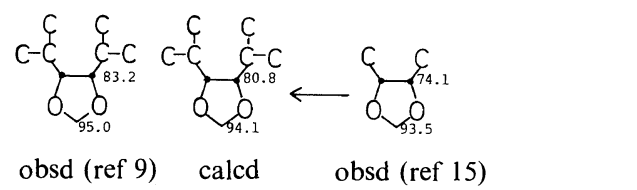

The error is relatively large for the bulky diisopropyl derivative even in the case of this very simple conversion.

\section{Cyclopolymerization Process}

Scheme 11 summarizes the cyclopolymerization process of divinyl ethers (DVE, PVE, and $\mathrm{CH}_{3}-$ PVE). The major course of propagation is common among these three monomers. The monomers react with growing radicals always at the unsubstituted side. The head-to-tail addition gives radical XXI which further reacts with monomer in the head-totail manner to produce radical XXII. This radical exclusively cyclizes in the head-to-head manner to give radical intermediate XXIII. The ring closure occurs in the trans manner, irrespective of the monomer structure. This cyclized radical undergoes either intermolecular propagation (formation of XXIV) or head-to-head cyclization (formation of XXV). The bicyclization process is again stereoselective, and the trans-fused structure is formed. The ease of cyclization $\left(k_{\mathrm{c}} / k_{\mathrm{p}}\right)$ is larger for substituted vinyl groups. The rate of polymerization and the molecular weight of the polymer become smaller, as the number of methyl substituents increases.

It is interesting that the monocyclization proceeds always via the trans ring closure. In the bicyclization process, the steric mode of ring closure is trans for PVE. There is no steric differentiation in the bicycli-
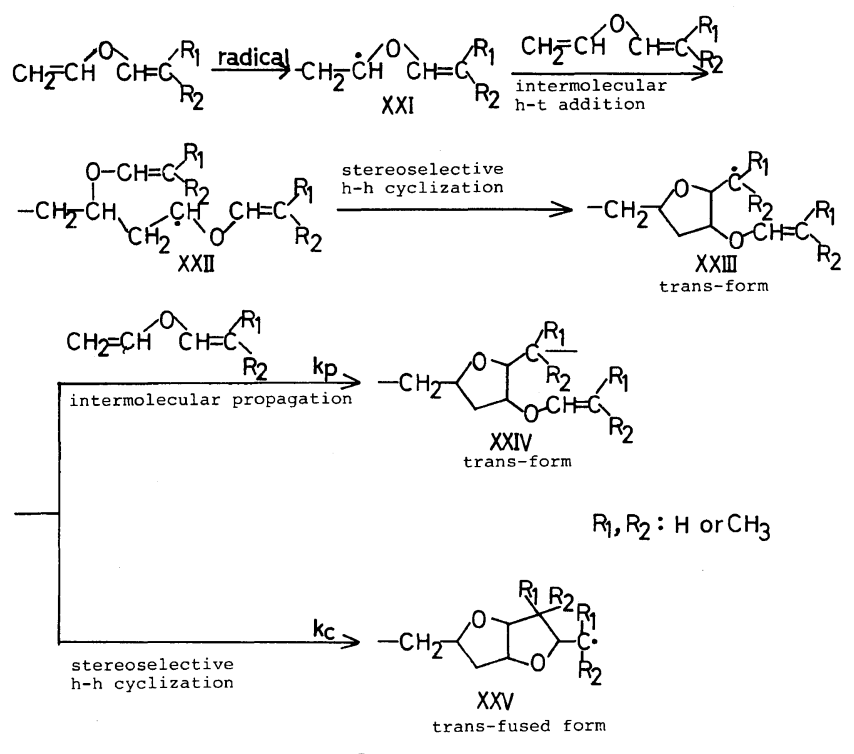

Scheme 11. 
zation of DVE and $\mathrm{CH}_{3}-\mathrm{PVE}$, since the cyclizing carbon is symmetircally substituted. The predominance of the trans ring closure is observed in the homopolymerization of 1,4-dienes (this study) as well as in their copolymerization. ${ }^{16}$ This is in contrast with the cis ring closure observed for monocyclization of 1,6-dienes. ${ }^{15,17.18}$ The five-membered ring is formed in both cases, but the stereochemistry of ring closure is reversed. Further study is required for a unified interpretation of these results.

The foregoing discussion is restricted to the major structural units. ${ }^{13} \mathrm{C}-\mathrm{NMR}$ spectra of poly(PVE) and poly $\left(\mathrm{CH}_{3}-\mathrm{PVE}\right)$ contain many small and/or broad peaks, in contrast to those of poly(DVE). The presence of minor structures cannot be denied for these polymers. One possible route leading to the minor structures is the hydrogen abstraction by the propagating radical in either the intramolecular (back-biting) or intermolecular (branching) manners. The complex spectra in the exocyclic carbon (25-35 ppm) and methyl carbon (10-20 ppm) regions found in Figures 7 and 10 point to these possibilities. Another possibility is the presence of sterically and/or geometrically isomeric strucrures. The increased methyl substitution certainly renders the situation complex.

Acknowledgement. The authors are grateful to Dr. Koichi Hatada of Osaka University for providing us with the preparation procedure for methallyl vinyl ether. We also appreciate the ${ }^{13} \mathrm{C}-\mathrm{NMR}$ measurement at elevated temperatures made by Dr. H. Mamezuka of Kyushu University.

\section{REFERENCES}

1. C. Aso and S. Ushio, Kogyo Kagaku Zasshi (J. Chem. Soc. Jpn., Ind. Chem. Sect.), 65, 2085 (1962).

2. C. Aso, S. Ushio, and M. Sogabe, Makromol. Chem., 100, 100 (1967).

3. M. Guaita, G. Camino, and L. Trossarelli, Makromol. Chem. 130, 243, 252 (1969); 131, 237 (1970); 149, 75 (1971).

4. T. Kunitake and M. Tsukino, Makromol. Chem., 177, 303 (1976).

5. M. Tsukino and T. Kunitake, Macromolecules, 12, 387 (1979).

6. W. H. Watanabe and L. E. Conlon, J. Am. Chem. Soc., 79, 2828 (1957).

7. C. C. Price and W. H. Snyder, Tetrahedron Lett., 69 (1962).

8. H. Yuki, K. Hatada, T. Emura, and K. Nagata, Bull. Chem. Soc. Jpn., 44, 537 (1971).

9. E. L. Eliel, V. S. Rao, and K. M. Pietrusiewicz, Org. Magn. Resonance, 12, 461 (1979).

10. J. Q. Adams and L. P. Lindeman, Prepr., Am. Chem. Soc., Div. Petrol. Chem., 17, C4 (1972).

11. M. Christl, H. J. Reich, and J. D. Roberts, J. Am. Chem. Soc., 93, 3463 (1971).

12. M. Fujiki, unpublished results in these laboratories.

13. A. Accary, J. Huet, and Y. Infarnet, Org. Magn. Resonance, 11, 287 (1978).

14. W. E. Willy, G. Binsch, and E. L. Eliel, J. Am. Chem. Soc., 92, 5394 (1970).

15. M. Tsukino and T. Kunitake, Polym. J., 11, 437 (1979).

16. T. Kunitake and M. Tsukino, J. Polym. Sci., Polym. Chem. Ed., 17, 877 (1979).

17. S. R. Johns, R. I. Willing, S. Middleton, and A. K. Ong, J. Macromol. Sci., Chem., A10, 875 (1976).

18. J. E. Lancaster, L. Baccei, and H. P. Panzer, J. Polym. Sci., Polym. Lett. Ed., 14, 549 (1976). 